\title{
SULT2A1 gene copy number variation is associated with urinary excretion rate of steroid sulfates
}

\author{
Jenny Schulze ${ }^{1}$, Maria Johansson ${ }^{1}$, John-Olof Thörngren ${ }^{2}$, Mats Garle ${ }^{1,2}$, Anders Rane ${ }^{1}$ and Lena Ekström ${ }^{1}$ * \\ ' Laboratory Medicine, Division Clinical Pharmacology, Karolinska Institutet, Stockholm, Sweden \\ 2 Doping Control Laboratory, Karolinska University Hospital, Stockholm, Sweden
}

\author{
Edited by: \\ Pei-San Tsai, University of Colorado, \\ USA

\section{Reviewed by:} \\ Valerie Langlois, Royal Military \\ College of Canada, Canada \\ Kaiping Yang, University of Western \\ Ontario, Canada \\ *Correspondence: \\ Lena Ekström, Division of Clinical \\ Pharmacology, Karolinska University \\ Hospital, C1-68, SE-14186 Stockholm, \\ Sweden \\ e-mail: lena.ekstrom@ki.se
}

Human cytosolic sulfotransferases (SULT) 2A1 is the main enzyme involved in the sulfate conjugation of dehydroepiandrosterone, a weak androgen, and the main androgen precursor, whereas estrogens are mainly conjugated by SULT1A1. Here we have identified a copy number variation (CNV) polymorphism in the SULT2A1 gene in a Swedish population including healthy men $(N=30)$. Moreover, the CNV of SULT1A1 and SULT2A1 was further characterized in relation to urinary levels of androgen sulfate metabolites before and after an intramuscular dose of $500 \mathrm{mg}$ testosterone enanthate. Individuals expressing two or more CNVs excrete 80 and $40 \%$ higher levels of DHEAS $(p=0.02)$ and androsteroneS ( $p=0.01$ ), respectively as compared to individuals with one gene copy. The mean area under the urine concentration time-curve from time 0 (prior to the administration of $500 \mathrm{mg}$ testosterone) to 15 days post dose values were $80 \%$ higher for DHEAS ( $p=0.046$ ) and testosteroneS $(p=0.019)$ in individuals with two and three SULT2A1 gene copies as compared to individuals with one gene copy. The SULT1A1 CNV on the other hand did not affect the sulfation activity toward the androgens. In conclusion our results indicate that functional CNV polymorphisms in SULT2A1 and SULT1A1 are common in a Swedish population and that SULT2A1 CNV is associated with the urinary concentrations of androgen sulfate metabolites.

Keywords: SULT2A1, SULT1A1, copy number variation, DHEAS, androgens, testosterone

\section{INTRODUCTION}

Human cytosolic sulfotransferases (SULT) enzymes catalyze the sulfate conjugations of many xenobiotics and endogenous compounds such as hormones. These reactions result in increased water solubility and enhanced urinary excretion of the conjugates. To date, 12 human SULT genes have been identified. Among these SULT1A1 (also known as P-PST) is an enzyme that has been well studied in relation to hormone related disease and detoxification of polycyclic aromatic hydrocarbons (1, 2). Another SULT member SULT2A1 (also known as DHEA ST) is highly expressed in human liver and catalyzes the sulfation of dehydroepiandrosterone (DHEA), the major steroid precursor in humans $(3,4)$. DHEA itself is a weak androgen which is converted into more active androgens in peripheral tissues $(5,6)$.

Large inter-individual variations in circulatory levels of DHEAS have been observed. Three SULT2A1 single nucleotide polymorphisms altering the amino acid sequence have been identified and associated with altered SULT2A1 activity and DHEA:DHEAS ratio in the circulation (7). Circulatory DHEAS is considered to represent the androgen pool and high concentration of DHEAS has been associated with diseases and disorders such, i.e., PCOS, cancer, and obesity $(8,9)$. In addition, the urinary concentration of DHEAS, as well as other androgen sulfates vary manifold between individuals (10-12). This large inter-individual variation in urinary excretion rate may be due to genetic variation in SULT enzymes; however this has not been studied.
A copy number variation (CNV) polymorphism has been identified in SULT1A1. It was shown that individuals display between one and five SULT1A1 gene copies and the number of gene copies have been associated with the enzyme activity (13). Recently it was found that SULT2A1 may exist in different CNVs (15). However, there are no studies confirming this CNV in a human population. $\mathrm{CNV}$ in other phase II hormone conjugating enzymes, i.e., uridine diphosphate-glucuronyltransferases (UGTs) has been well characterized (14). We have previously shown that a large extent of the variation of urinary concentration of androgen glucuronides can be ascribed to genetic variation in (UGTs). A CNV of UGT2B17 is strongly associated with testosterone-glucuronide concentrations in urine, both at baseline (15) and after the administration of a supra-physiological dose of testosterone (16).

Here we aim to investigate if SULT2A1 display variation in copy numbers in a Swedish population, and if there is an association with SULT1A1 and SULT2A1 CNV genotype and the urinary excretion of different androgen sulfates prior to and after the administration of testosterone.

\section{MATERIALS AND METHODS SUBJECTS AND DESIGN}

Study subjects included 30 healthy male volunteers aged 1850 years. The study population has been described in more detail elsewhere (16). All participants gave informed consent consistent with the approval of the Ethics Review Board, Karolinska Institutet, Stockholm. The participants were given $500 \mathrm{mg}$ testosterone 
enanthate as a single intra muscular (i.m) dose of Testoviron Depot (kindly provided by Schering Nordiska AB, Solna, Sweden) equivalent to $360 \mathrm{mg}$ testosterone. Urine samples were collected for analyses before administration (day 0) and on days 1-9, 11, 13, and 15 after dose. All samples were collected between 07:00 and 11:00 h. Adverse drug reactions were monitored during the study period. No major adverse drug reactions were registered. No follow-up was needed. The study was conducted according to the Helsinki Declaration and the ICH Harmonized Tripartite Guideline for Good Clinical Practice.

\section{URINARY ANALYSIS}

The concentrations of sulfated androgens were analyzed using a LC-MS/MS method as previously described (10). Briefly, $1 \mathrm{~mL}$ and 20 IL ISTD samples were added to SPE Oasis HLB 96-well plates and washed with $0.1 \%$ acetic acid, $0.1 \%$ ammonia, and $10 \%$ $\mathrm{MeOH}$. The analytes were eluted with acetone and after evaporation the residue was reconstituted with $20 \% \mathrm{MeOH}$. Waters Acquity ultra performance liquid chromatographic (UPLC) system was used to perform the separation on Waters Acquity UPLC BEH RP18 column $5092.1 \mathrm{~mm}$ with $1.7 \mathrm{~lm}$ particles. The mobile phases were $5 \mathrm{mM}$ NH4Ac adjusted by ammonia to $\mathrm{pH} 9.6$ (A) and $\mathrm{MeOH}$ (B). A Waters Micromass Quattro Premier triple-quadrupole instrument (Waters Associates, Manchester, UK) operating with fast polarity switching in multiple reaction mode (MRM) was used to detect the target analytes.

\section{SULT1A1 AND SULT2A1 GENE COPY NUMBER VARIATION}

Genomic DNA was extracted from $200 \mu \mathrm{L}$ blood using Qiagen Mini Kit. Twenty nanograms genomic DNA was used in each reaction together with 2X TaqMan Universal Master Mix (Applied Biosystems, Foster City, CA, USA). The SULT1A1 and SULT2A1 $\mathrm{CNV}$ polymorphisms were analyzed by real-time polymerase chain reaction analysis using premade assays Hs04461762_cn and Hs03013147_cn (Applied Biosystems). Expression of albumin was quantified as an endogenous control as described (17). Both reactions were run in $15 \mu \mathrm{L}$ reactions. The PCR profile consisted of an initial denaturation step at $95^{\circ} \mathrm{C}$ for $10 \mathrm{~min}$ followed by 40 cycles of $92^{\circ} \mathrm{C}$ for $15 \mathrm{~s}$ and $60^{\circ} \mathrm{C}$ for $1 \mathrm{~min}$.

\section{DATA EVALUATION}

Integration, calibration, and data evaluation was performed by the TargetLynx software (Waters Associates, Manchester, UK). The between subject variation in urine dilution was corrected for by dividing the concentration values by the urinary creatinine (cr) concentration, which was determined by colorimetric analysis (DRI Creatinine-Detect Test; Thermo Fisher Scientific, Waltham, MA, USA). The areas under the curve (AUC) of the different urinary steroids were calculated using the trapezoidal rule. Statistical analyses were performed by Kruskal Wallis followed by Dunn's Multiple Comparison Test, since the data were not normally distributed.

\section{RESULTS}

\section{GENE COPY NUMBER ANALYSIS}

The distribution of SULT1A1 copy numbers were; individuals with one gene copy (i.e., one deletion) $N=6(20 \%)$, two copies $N=16(53 \%)$, and three copies $N=8(26 \%)$, respectively. The distribution of SULT2A1 copy numbers were; individuals with one copy $N=7(23 \%)$, two copies $N=9(60 \%)$, and three gene copies $N=4(13 \%)$, respectively.

\section{SULT1A1 AND SULT2A1 CNV AND URINARY BASELINE LEVELS OF STEROID SULFATES}

There was a significant correlation between urinary concentration of DHEAS $(p=0.02)$ and androsteroneS $(p=0.01)$ and the number of SULT2A1 CNV, Figures 1A,B. Individuals displaying one SULT2A1 gene copy excreted lower levels of DHEAS and androsteroneS $(8.8$ and $22.9 \mathrm{ng} / \mu \mathrm{mol} \mathrm{cr}$ ) compared to individuals with two copies $(44.5$ and $53.6 \mathrm{ng} / \mu \mathrm{mol} \mathrm{cr}$ ) and three SULT2A1 gene copies ( 48.5 and $60.1 \mathrm{ng} / \mu \mathrm{mol} \mathrm{cr}$ ). There were no significant correlation between SUL2A1 CNV and urinary concentration of testosteroneS and etiocholanoloneS, Figures 1C,D. There was no significant association between SULT1A1 CNV and urinary levels of any androgen sulfates investigated.

\section{SULT2A1 CNV AND URINARY AUC OF STEROID SULFATES POST TESTOSTERONE ADMINISTRATION}

The mean AUC for DHEAS during 15 days post dose were 44.5, 279 , and $300 \mathrm{ng} / \mu \mathrm{mol} \mathrm{cr}$ in individuals with one, two, and three gene copies, respectively ( $p=0.046$ ), Figure $2 \mathrm{~A}$. The mean AUC for testosteroneS during 15 days were $2.2,7.4$, and $11.6 \mathrm{nmol} / \mu \mathrm{mol}$ $\mathrm{cr}$ in individuals with one, two, and three gene copies, respectively $(p=0.019)$, Figure 2B. There were no significant correlations between urinary AUC for etiocholanoloneS, androsteroneS, and SULT2A1 CNV, Figures 2C,D.

There were no significant association between SULT1A1 CNV and urinary AUC of androgen sulfates investigated.

\section{DISCUSSION}

Piper et al. showed that there is a large inter-individual variation (500-fold) in the urinary excretion rate of DHEAS (11). However, there are no studies investigating the inter-individual variability of urinary levels of DHEAS in relation to genotype. We show for the first time that SULT2A1 CNV is functional and that the number of SULT2A1 copies is associated with the baseline concentration of DHEAS, as well as the baseline concentration of the DHEA metabolite androsterone. In vitro studies have shown that in addition to DHEA, SULT2A1 also possesses high sulfation activity toward androsterone (4). There was lower sulfation activity in individuals with one SULT2A1 copy compared to individuals with two or more copies for all steroid metabolites investigated except etiocholanoloneS. Our results demonstrate that SULT2A1 exerts activity not only toward DHEA but also toward several DHEA metabolites in vivo.

After administration of exogenous testosterone to healthy volunteers, the urinary excretion rate of sulfate metabolites was significantly associated with SULT2A1 CNV. The urinary concentration of DHEAS and testosteroneS decreased approximately 50 and $80 \%$ respectively, after the administration of testosterone enanthate. This is probably a result of a feedback mechanism on the hypothalamic-pituitary axis. However, a significant SULT2A1 genotype association with the excretion of both DHEAS and testosteroneS, even at the low concentrations observed post dose further strengthen the finding that DHEA and testosterone are substrates of SULT2A1 in vivo. On the other hand the urinary 

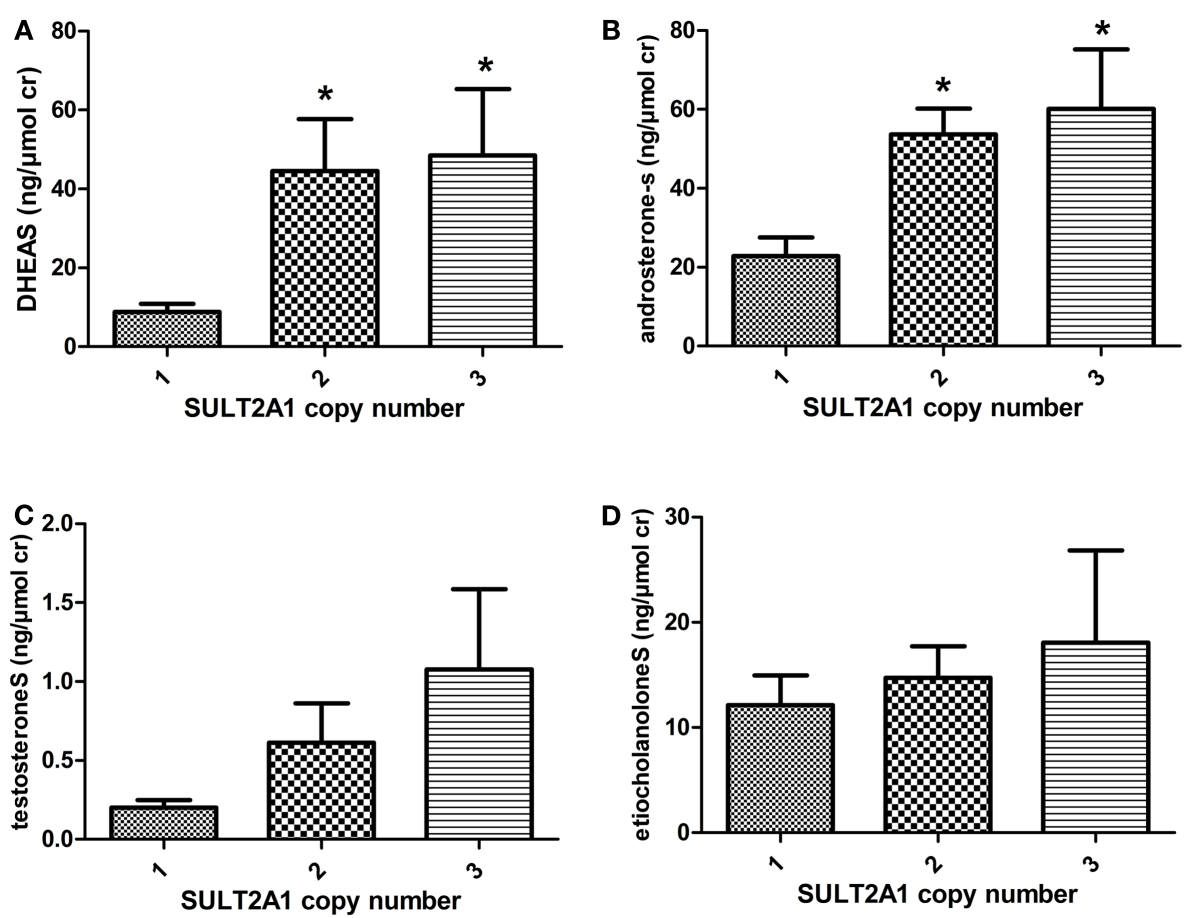

FIGURE 1 | The mean urinary concentration of (A) DHEAS (B) androsteroneS (C) testosteroneS and (D) etiocholanoloneS in different SULT2A1 genotype panels. The androgen conjugate concentration was

normalized against creatinine (cr) concentration. Individuals with two and three SULT2A copy number variation excrete higher levels of DHEAS and androsteroneS.
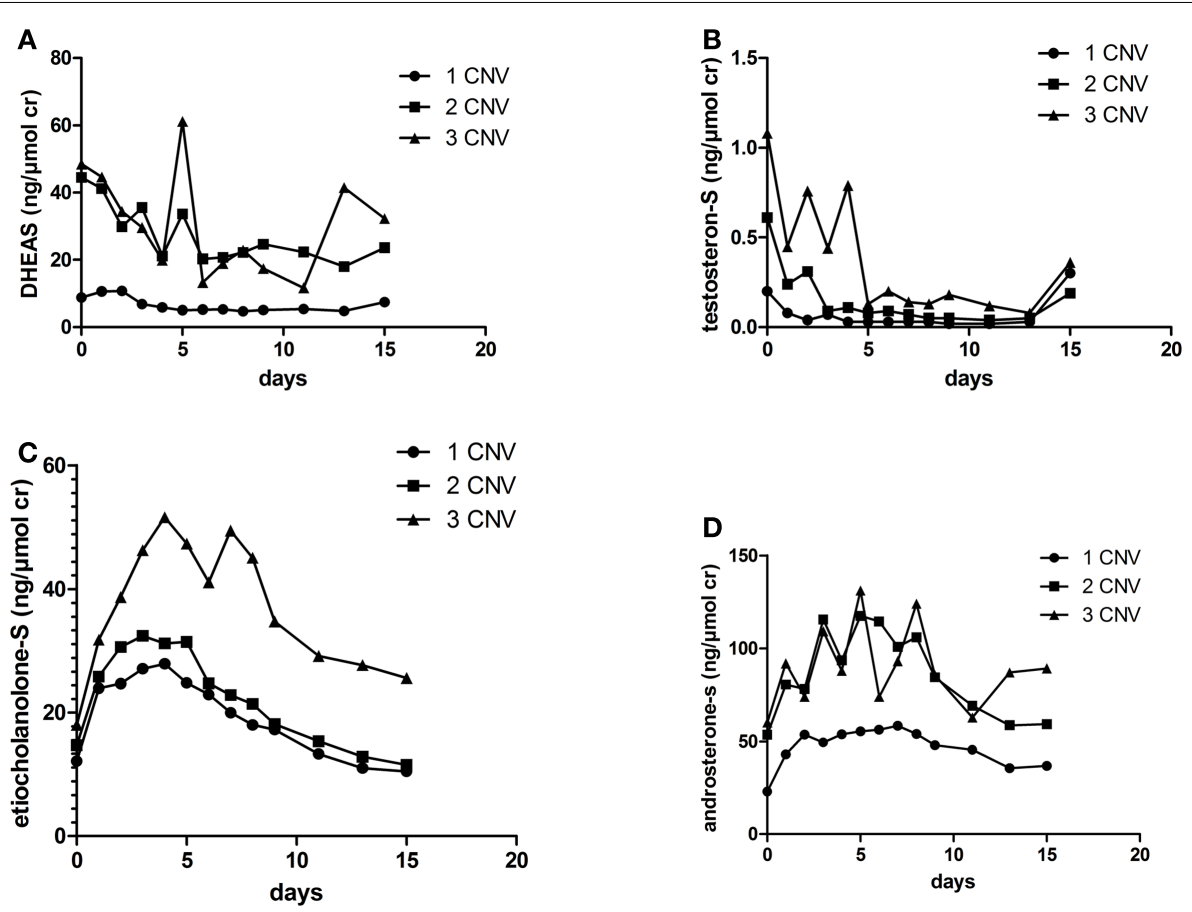

FIGURE 2 | Urinary (A) DHEAS (B) testosteroneS (C) etiocholanoloneS and (D) androsteroneS excretion (ng/ $\mu$ mol) for 15 days in the different SULT2A1 genotype groups after an i.m injection of $500 \mathrm{mg}$ testosterone enanthate. 
levels of the testosterone metabolites androsteroneS and etiocholanoloneS increased as a result of the administrated testosterone. The association between CNV of SULT2A1 and AUC of androsteroneS was not statistically significant. However as the study sample was small with only seven individuals with one gene copy, the power might have been insufficient to demonstrate any significance. Our AUC results are in agreement with our baseline finding, supporting that these androgen metabolites are sulfated by SULT2A1 in vivo.

The allele distribution of SULT1A1 was in agreement with a previous study reporting a $25 \%$ frequency of three SULT1A1 copies in Caucasians (13) but opposite to other studies reporting a $5 \%$ occurrence of one copy number $(13,18)$. There was no correlation between CNV of SULT1A1 and the urine concentration of the steroid sulfates. Even though SULT1A1 has been shown to be involved in hormone metabolism, this enzyme has been shown to be more important in the sulfation of estrogens (2).

For ethical and medical reason, testosterone was administered to men only. Sulfation of androgens are important also in women, and genetic variation in different SULTs have been associated with altered risk for PCOS and breast cancer treatment $(19,20)$ and it would be of interest to study this functional CNV in relation to the metabolism of endogenous and exogenous androgens in females in future studies.

DHEAS is found at high concentrations in the circulation and has in addition to hormone related cancers and PCOS also been shown to be involved in the risk of cardiovascular diseases

\section{REFERENCES}

1. Zhang L, Huang M, Blair IA, Penning TM. Detoxication of benzo[a]pyrene-7,8-dione by sulfotransferases (SULTs) in human lung cells. $J$ Biol Chem (2012) 287:29909-20. doi:10.1074/jbc.M112.386052

2. Hempel N, Gamage N, Martin JL, McManus ME. Human cytosolic sulfotransferase SULT1A1. Int $J$ Biochem Cell Biol (2007) 39:685-9. doi:10.1016/j.biocel.2006.10.002

3. Hernandez JS, Watson RW, Wood TC, Weinshilboum RM. Sulfation of estrone and 17 beta-estradiol in human liver. Catalysis by thermostable phenol sulfotransferase and by dehydroepiandrosterone sulfotransferase. Drug Metab Dispos (1992) 20:413-22.

4. Falany CN, Vazquez ME, Kalb JM. Purification and characterization of human liver dehydroepiandrosterone sulphotransferase. Biochem $J$ (1989) 260:641-6.

5. Labrie F, Dupont A, Simard J, LuuThe $\mathrm{V}$, Belanger A. Intracrinology: the basis for the rational design of endocrine therapy at all stages of prostate cancer. Eur Urol (1993) 24(Suppl 2):94-105.

6. Labrie F, Belanger A, Cusan L, Candas B. Physiological changes

$(21,22)$. SULT2A1 expression is down-regulated in hepatocellular carcinoma and correlated with higher grade and stage of cancer (23). Additionally, SULT2A1 has been shown to be involved in the metabolism and activation of carcinogenic compounds and drugs $(24,25)$. It is possible that SULT2A1 CNV polymorphism may contribute to individual variation in response to drugs that undergo sulfation as well as altered risk for cancer and other diseases.

Variability in CNV is a common phenomenon in the human genome, and has been observed for a number of enzymes involved in biotransformation, i.e., UGT2B17, CYP2D6, and GSTM (26). This is the first time SULT2A1 CNV has been studied in a human population, and our results confirm that this putative polymorphism exists. According to the provider (Applied Biosystems) of the SULT2A1 gene copy assay used in this study the deletion consists of $2849 \mathrm{bp}$ at the $3^{\prime}$-end of the SULT2A1 gene, at chromosome position 19q13.33. Jung et al. identified a $150000 \mathrm{bp}$ homozygous SULT2A1 gene deletion at position $19 q 13.32$ in a pulmonary inflammatory myofibroblastic tumor (27). It is possible that different CNV exists throughout the SULT2A1 gene. Further studies are warranted in order to characterize the genetic make-up of this $\mathrm{CNV}$ and the phenotypic consequences.

\section{ACKNOWLEDGMENTS}

This work was supported by grants from World Anti Doping Agency (WADA) and Swedish National Centre for Research in Sports.

Endocrinol Metab (2011) 96:3440 7. doi:10.1210/jc.2011-0521

11. Piper T, Opfermann G, Thevis M, Schanzer W. Determination of (13) C/(12)C ratios of endogenous urinary steroids excreted as sulpho conjugates. Rapid Commun Mass Spectrom (2010) 24:3171-81. doi: $10.1002 / \mathrm{rcm} .4762$

12. Sten T, Bichlmaier I, Kuuranne $\mathrm{T}$, Leinonen $\mathrm{A}$, Yli-Kauhaluoma J, Finel $\mathrm{M}$. UDP-glucuronosyltransferases (UGTs) 2B7 and UGT2B17 display converse specificity in testosterone and epitestosterone glucuronidation, whereas UGT2A1 conjugates both androgens similarly. Drug Metab Dispos (2009) 37:417-23. doi:10.1124/dmd.108.024844

13. Hebbring SJ, Adjei AA, Baer JL, Jenkins GD, Zhang J, Cunningham JM, et al. Human SULT1A1 gene: copy number differences and functional implications. Hum Mol Genet (2007) 16:463-70. doi:10.1093/hmg/ddl468

14. Menard V, Eap O, Harvey M, Guillemette C, Levesque E. Copy-number variations (CNVs) of the human sex steroid metabolizing genes UGT2B17 and UGT2B28 and their associations with a UGT2B15 functional polymorphism.
Hum Mutat (2009) 30:1310-9. doi:10.1002/humu.21054

15. Jakobsson J, Ekstrom L, Inotsume N, Garle M, Lorentzon M, Ohlsson $\mathrm{C}$, et al. Large differences in testosterone excretion in Korean and Swedish men are strongly associated with a UDP-glucuronosyl transferase 2B17 polymorphism. J Clin Endocrinol Metab (2006) 91:687-93. doi:10.1210/jc.20051643

16. Schulze JJ, Lundmark J, Garle M, Skilving I, Ekstrom L, Rane A. Doping test results dependent on genotype of uridine diphosphoglucuronosyl transferase 2B17, the major enzyme for testosterone glucuronidation. J Clin Endocrinol Metab (2008) 93:25006. doi:10.1210/jc.2008-0218

17. Schaeffeler E, Schwab M, Eichelbaum M, Zanger UM. CYP2D6 genotyping strategy based on gene copy number determination by TaqMan real-time PCR. Hum Mutat (2003) 22:476-85. doi:10.1002/humu.10280

18. Gaedigk A, Twist GP, Leeder JS. CYP2D6, SULT1A1 and UGT2B17 copy number variation: quantitative detection by multiplex PCR. Pharmacogenomics (2012) 13:91-111. doi:10.2217/pgs.11.135 
Schulze et al.

SULT2A1 CNV and steroid sulfates

19. Goodarzi MO, Antoine HJ, Azziz R. Genes for enzymes regulating dehydroepiandrosterone sulfonaion are associated with levels of dehydroepiandrosterone sulfate in polycystic ovary syndrome. J Chin Endocrinol Metal (2007) 92:265964. doi:10.1210/jc.2006-2600

20. Gjerde J, Hauglid M, Breilid $H$, Lundgren S, Varhaug JE, Kisanga ER, et al. Effects of CYP2D6 and SULT1A1 genotypes including SULT1A1 gene copy number on tamoxifen metabolist. Ann Oncol (2008) 19:56-61. doi:10.1093/annonc/mdm434

21. Barrett-Connor E, Khat KT, Yen SS. A prospective study of dehydroepiandrosterone subfate, mortality, and cardiovascular disease. $N$ Encl J Med (1986) 315:1519-24. doi:10.1056/ NEJM198612113152405

22. Mitchell LE, Sprecher DL, Borecki IB, Rice T, Laskarzewski PM, Rao
DC. Evidence for an associatimon between dehydroepiandrosterone sulfate and nonfatal, peremature myocardial infarction in males. Circulation (1994) 89:8993. doi:10.1161/01.CIR.89.1.89

23. Huang LR, Coughtrie MW, Hsu HC. Down-regulation of dehydroepiandrosterone subfotransferase gene in human hepatocellular carcinoma. $\mathrm{Mol}$ Cell Endocrinol (2005) 231:87-94. doi:10.1016/j.mce.2004.10.002

24. Slat H, Pauly K, Czich A, Falany JL, Falany CN. Activation of benzylic alcohols to mutagens by rat and human sulfotransferases expressed in Escherichia coli. Eur J Pharmacol (1995) 293:173-81. doi:10.1016/09266917(95)90002-0

25. Kurogi K, Chen M, Lee Y, Chi B, Yam T, Lu MY, et al. Sulfation of buprenorphine, pentazocine, and naloxone by human cytosolic sulfotransferases. Drug Metal Lett (2012) 6:109-15. doi:10.2174/187231212804096673

26. Ingelman-Sundberg $M$, Sim SC, Gomez A, Rodriguez-Antona C. Influence of cytochrome P450 polymorphisms on drug therapies: pharmacogenetic, pharmacoepigenetic and chincal aspects. Pharmacol The (2007) 116:496-526. doi:10.1016/ j.pharmthera.2007.09.004

27. Jung $\mathrm{SH}$, Mim $\mathrm{SH}, \mathrm{Hu} \mathrm{HJ}$, Jung $\mathrm{CK}$, Lee $\mathrm{SH}$, Kim $\mathrm{DH}$, et al. Copy number alterations and expression profiles of candidate genes in a pulmonary inflamematory myofibroblastic tumor. Lung Cancer (2010) 70:152-7. doi:10.1016/j.lungcan.2010.01.019

Conflict of Interest Statement: The authors declare that the research was conducted in the absence of any commercial or financial relationships that could be construed as a potential conflick of interest.

Received: 03 May 2013; accepted: 01 July 2013; published online: 12 July 2013.

Citation: Schulze J, Johnson M, Thorngran J-O, Earle $M$, Rave $A$ and Ekström L (2013) SULT2A1 gene copy number variation is associated with urinary excretion rate of steroid subfates. Front. Endocrinol. 4:88. do: 10.3389/fendo.2013.00088

This article was submitted to Frontiers in Experimental Endocrinology, a specialty of Frontiers in Endocrinology.

Copyright (c) 2013 Schulze, Johnson, Thörngren, Earle, Rave and Ekström. This is an open-access article distributed under the terms of the Creative Commons Attribution License, which perwits use, distribution and reproduction in other forums, provided the original authors and source are credited and subjest to any copyright notices concerning any third-party graphics etc.

www.frontiersin.org

July 2013 | Volume 4 | Article 88 | 5 